\title{
¡Deje hablar! La transferencia en "Las desdichas de Cardenio" de Don Quijote de la Mancha
}

\author{
Let speak! Transference in "Cardenio's Grieves" from \\ Don Quixote de la Mancha
}

Oswaldo Ortegón Cufiño ${ }^{1}$

Resumen

Entre los distintos estudios que relacionan la literatura de creación con el psicoanálisis clínico y su comprensión metapsicológica, se destaca el papel ilustrador del arte y la literatura en la explicación del pensamiento psicoanalítico. Este trabajo discute el concepto fundamental de la transferencia, teniendo como referente la locura de Cardenio, un personaje de Don Quijote de la Mancha. Varios elementos técnicos del quehacer psicoanalítico florecen alrededor del estudio de esta idea.

\section{Palabras clave}

Psicoanálisis, literatura, Don Quijote, Cardenio, sexualidad, transferencia, contra-transferencia, perspectivismo.

Abstract

Different studies that relate creative literature to clinical psychoanalysis and its meta-psychological understanding, have highlighted the illustrative role of art and literature in the explanation of psychoanalytic thought. This paper discusses the fundamental concept of transference, using the madness of Cardenio, a character in don Quixote de la Mancha, as a reference. Some technical elements of this psychoanalytic work are developed through the study of this idea.

Key words:

Psychoanalysis, literature, don Quixote, Cardenio, sexuality, transference, counter transference, perspectivism.

Artículo recibido el 17 de mayo de 2011 y aprobado el 19 de agosto de 2011

1 University of Kentucky. Correo electrónico: oswaldoortegon@gmail.com 


\section{Introducción}

La riqueza de la novela cervantina, como primera novela moderna, permite su aproximación y estudio desde diversos y variados punto de vista. Desde una visión psicoanalítica, se han realizado trabajos dirigidos a develar las profundas correspondencias existentes entre el psicoanálisis y algunas obras de Cervantes, especialmente con El Quijote (1616). Algunos de estos estudios relacionados en las páginas siguientes demuestran, efectivamente, la fuerte influencia de Cervantes en el desarrollo del pensamiento psicoanalítico. La sexualidad, el deseo, la represión, la repetición, el complejo de Edipo, el chiste y sus relaciones con el inconsciente, entre otros tantos temas, son estudiados en muchos de estos escritos gracias al largo recorrido de Don Quijote por los diferentes capítulos de la obra. La articulación del saber literario con la teoría científica encuentra en algunas de las obras de Cervantes y en el pensamiento de Freud su mejor forma de expresión.

Si bien la mayoría de los estudios psicoanalíticos sobre El Quijote analizan el desarrollo, conflicto, comportamiento y acontecer de sus personajes de acuerdo con los postulados teóricos del psicoanálisis planteados por Freud y Lacan, especialmente, la aplicación clínica de esta terapia dirigida a la recuperación de los enfermos de "locura" no parece tener gran desarrollo en la mayoría de los estudios observados, tal vez, por las dificultades que entraña intentar entrar en terapia a un personaje de ficción que solamente vive, en principio, para los propósitos de la obra. No siendo mi interés otro que el de analizar de manera didáctica y organizada el funcionamiento del fenómeno de la transferencia como uno de los conceptos fundamentales del psicoanálisis y elemento clave en el desarrollo de la técnica clínica, observo el caso de Cardenio, uno de los personajes que conforman la polifónica obra cervantina, para intentar despejar esta hipótesis. Si la «transferencia es motor y obstáculo para la cura», se debe de realizar entonces un profundo análisis sobre la "locura" de Cardenio, alter ego de Don Quijote (Freud, 2006, p. 1649).

\section{Objetivo}

En este trabajo analizo la mini-historia de Cardenio - uno de los alter ego de Don Quijote de la Mancha- (capítulos XXIII al XXVIII) para reconocer, de manera particular, elementos ilustradores en la formación del concepto psicoanalítico de transferencia. En el desarrollo de esta idea, se puede observar cómo la riqueza de la novela cervantina es de utilidad para el entendimiento y comprensión de la teoría psicoanalítica.

\section{Freud, el español y Cervantes}

Las relaciones de Sigmund Freud con la literatura de creación son tan pretéritas como sus deseos e intenciones de conocer el funcionamiento de la psiquis. En la literatura, el joven Sigmund observó información de utilidad reveladora en su largo proceso de investigación clínica y teorización psicoanalítica. Freud leyó a Goethe a los ocho años, y a los quince aprendió español ${ }^{2}$ para leer algunas de las obras de Cervantes y conocer más de cerca el sentido de los textos. Para Freud, también estudioso de la antropología y de otras ciencias humanas, aprender la lengua de su población de trabajo o de algunos de los textos literarios que inspiraban sus análisis, era quizás importante debido a que «language of the people offers clues, perhaps even the key, to its culture ${ }^{3}$ 》 (Fabian, 106). De los textos de origen español, llamaron especialmente su atención $E l$ ingenioso hidalgo Don Quijote de la Mancha (1605) y El coloquio de los perros ${ }^{4}$ (1613), muy seguramente

2 Freud, a los 65 años de edad, escribió una carta al traductor de su obra al castellano. La carta dice: «Sr. D. Luis López-Ballesteros y de Torres. Siendo yo un joven estudiante, el deseo de leer el inmortal "Don Quijote" en el original cervantino me llevó a aprender, sin maestros, la bella lengua castellana. Gracias a esta afición juvenil puedo ahora - ya en edad avanzada - comprobar el acierto de su versión española de mis obras, cuya lectura me produce siempre un vivo agrado por la correctísima interpretación de mi pensamiento y la elegancia del estilo. Me admira, sobre todo, cómo no siendo usted médico ni psiquiatra de profesión ha podido alcanzar tan absoluto y preciso dominio de una materia harto intrincada y a veces oscuran. Freud, Viena, 7 de mayo de 1923 (Freud, S., 2006).

3 Es mi traducción: se considera que «el lenguaje de la gente ofrece rastros, o tal vez incluso, claves de su cultura».

4 Precisa Edward Calverley Riley que en las cartas escritas por Freud a Eduard Silbertein, su amigo de adolescencia, entre los años 18711881, se observa que contienen buena información acerca de las actividades juveniles de Freud, sus opiniones, aspiraciones y sus 
por la forma como desde la ficción, Cervantes dibuja figuras específicas que representan el funcionamiento del comportamiento humano. El joven Sigmund, al acercarse a estos textos, elabora quizás y sin ser muy consciente de ello, sus primeros ejercicios de análisis aplicado, al observar ilustraciones maravillosas e intuir pronunciamientos subjetivos útiles en la futura construcción de la teoría psicoanalítica5.

\section{¿Quién es y por qué Cardenio?}

Entre los setecientos setenta y siete (777) personajes rodando y reinterpretando acontecimientos y facetas humanas en El Quijote, llaman la atención Cardenio y su entorno, no sólo por reproducir de nuevo el papel de víctima en los juegos de fidelidad y amor, característico de algunos personajes de origen andaluz desplegados en la obra, sino por representar un típico caso de locura ${ }^{6}$ válido para el

intereses científicos, filosóficos y literarios, así como de su vida emocional para aquella época. Igualmente, hay ejemplos sobre escritos creativos de diferentes tipos, pero en particular, uno que Freud comenta a su prometida Martha Bernays en carta fechada el 07 de febrero de 1884 sobre la relación de amistad y de trabajo que tenía con su amigo Eduard, con quien formaron una sociedad secreta llamada La Academia Española. Ellos, dentro de esta sociedad de amigos, se hacen llamar a sí mismos como Cipión y Berganza en analogía burlesca a los personajes del Coloquio de los perros, una de las novelas ejemplares de Cervantes. Freud le comenta a Martha que: «We learned Spanish together, had our own mythology and secret names, which we took from some dialogue of the great Cervantes. Once in our Spanish primer we found a humorous-philosophical conversation between two dogs which lie peacefully at the door of a hospital, and appropriated their names; in writing as well as in conversation he was known as Berganza, I as Cipion. How often have I written: Querido Berganza! and signed myself Tu fidel Cipio, pero en el Hospital de Sevilla [sic]. Together we founded a strange scholarly society, the "Academia Castellana" (AC), compiled a great mass of humorous work which must still exist somewhere among my old papers». Para más información véase Riley, Edward C., 1994 y Grinberg, León y Rodríguez Francisco, 1993.

5 Utilizo el concepto de análisis aplicado teniendo en cuenta el desarrollo freudiano y lacaniano del concepto estudiado por Belén Moreno en Un oficio literal. Aunque como bien lo precisa la ensayista, "el concepto de ilustración puede leerse en dos sentidos con aproximaciones metodológicas opuestas", considero que para el caso en estudio se complementan (Moreno Cardozo, B. del R., 2009).

6 La historia de Cardenio se inscribe en la Europa del siglo XVII que concibe la locura como un acto irracional, animal, miserable, desgraciado y vergonzante, comparable a la lepra, o, como una resonancia de ésta. La política del aislamiento, como una forma de exclusión social de los considerados locos, se reajusta a través de los años venideros hasta cuando cesa el temor por la "enfermedad" de la locura, debido a la aceptación paulatina de otras nuevas formas de racionalidad. La decreciente influencia social de la religión análisis y aplicación de algunos conceptos y técnicas del quehacer psicoanalítico, como el de la transferencia y la contratransferencia. Gracias a la naturaleza polifónica de El Quijote y a la reproducción exponencial de sus personajes, se puede rastrear el desarrollo y confirmación de esta hipótesis a través del desempeño y accionar de Cardenio.

En su relato autobiográfico, Cardenio revela su nombre y agrega que es de transparente linaje. Se manifiesta enamorado desde su infancia de la hermosa Luscinda, que le había correspondido tiernamente. Desafortunadamente, sus indecisiones y timidez perturban esta sencilla historia de amor, debido a que su amigo Fernando, hijo segundo de un poderoso duque, es un joven elegante, frívolo y mujeriego que, después de haber seducido a una bella labradora con la promesa falaz de casarse con ella, se retira al pueblo, a la casa de Cardenio, para olvidar su capricho amoroso. Cardenio ingenuamente describe a Luscinda a este "Don Juan", e incluso se la señala al reflejo de la luz de una candela. Se despierta un gran apetito erótico en don Fernando, y en Cardenio se enciende la llama de los celos. La desilusión de Cardenio es total al descubrir días después a don Fernando y a Luscinda en ceremonia matrimonial. Como se siente convencido de la traición de Luscinda se interna en Sierra Morena a vivir sus desventuras. Adolorido anímicamente, comenta una y otra vez estos hechos a quien tropieza en su camino, sin posibilidades de recuperar la cordura.

El desventurado Cardenio, en el encuentro con el otro, reiterativamente trata de hacer catarsis para aliviar su dolor. Según manifiesta el cabrero, quien es el primero en referenciarlo, a todos los que intentan entrar en contacto con él para alimentarlo, saber algo de sus dolencias y de su particular modo de vida, éste insulta y golpea cuando se le interrumpe en su hablar. Luego se interna de nuevo en la montaña haciendo apariciones intermitentes en los caminos (Cervantes, p. 158). Cardenio, el Caballero del Bosque, como también lo denomina el ingenioso hidalgo

por efectos de la modernidad es clave en este proceso. La iglesia católica se proyecta, luego, en una actitud de caridad y servicio con los “locos" (Foucault, M., 1961). 
a su encuentro con éste y con Sancho, condiciona su hablar a que Don Quijote: «con ninguna pregunta ni con otra cosa no interrumpiréis el hilo de mi triste historia, porque en tal punto que lo hagáis, en ese quedará lo que fue contado» (Óp. Cit., 161). Sin embargo Don Quijote, acostumbrado a interrumpir las conversaciones para destacar su ingenio, demostrar su caballerosidad y dar consejos, rompe igualmente con las exigencias planteadas por Cardenio y recibe la misma lección dada con anterioridad al cabrero y a los demás ganaderos de la región: una golpiza como lección para que aprenda a escuchar (el subrayado es mío).

\section{Introspección a Cardenio por parte de Don Quijote}

En la mini historia de Cardenio, la voz narrativa dice que este personaje está loco por amor. La conducta aparentemente infiel de su amada Luscinda lo llevó a internarse en Sierra Morena donde, según anota Don Quijote, vive como un animal:

\begin{abstract}
Yo os suplico, señor, -le dice Don Quijote a Cardenio- que me digáis quién sois y la causa que os ha traído a vivir y a morir entre estas soledades como bruto animal, pues moráis entre ellos tan ajeno de vos mismo cual lo muestra vuestro traje y persona (Óp. Cit., p. 161).
\end{abstract}

Don Quijote se hace a una primera impresión del estado mental de Cardenio e intuye la necesidad de iniciar con él un ejercicio de introspección dialógica dirigido a la recuperación de su locura. Le dice Don Quijote a Cardenio:

Tanto que tenía determinado no salir destas tierras hasta hallaros, y saber de vos si al dolor que en la extrañeza de vuestra vida mostráis tener, se podía hallar algún género de remedio, y si fuera menester buscarle, buscarle con la diligencia posible (Óp. Cit., p. 161).

La narración continúa en forma ordenada y secuencial con el despliegue de varias escenas dialógicas reveladoras de elementos funcionales de la terapia psicoanalítica ilustrada hábilmente desde el siglo XVII por el autor de El Quijote.

\section{Perspectivismo y analogías con la locura de Cardenio}

Cervantes construye parte de sus mini relatos recurriendo a la técnica del perspectivismo narrativo ${ }^{7}$. Esta visión de conjunto, propia de la naturaleza de la novela en cuanto a género literario, le sirve para presentar a un Cardenio funcionando como un alter ego más de Don Quijote. El uso de esta técnica literaria permite, asimismo, elaborar una analogía con el psicoanálisis para explicar el funcionamiento del síntoma en la vida inconsciente de Cardenio y los hechos de Sierra Morena. A propósito de la locura padecida por Cardenio, se puede recurrir a esta comparación para describir y hacer más gráfico el funcionamiento de la mente humana. Los síntomas de su enfermedad, (¿neurosis de angustia?) $)^{8}$ son comparables en el relato a sus inesperadas apariciones a los cabreros, a Don Quijote, al cura y al barbero en Sierra Morena. Él, como el síntoma, es empujado hacia la realidad exterior pero choca con las barreras del yo (los ganaderos, el cabrero, Don Quijote y Sancho) que lo envían de regreso a sumergirse en el mundo del inconsciente, como el de Sierra Morena, en donde reiterativamente se esconde después de sus imprevistas y violentas salidas:

7 Varios autores han señalado la importancia del perspectivismo en el Quijote. Jean Casaou, por ejemplo, subraya esta técnica como expresión de la ambigüedad, complicación y multiplicación de puntos de vista de la época renacentista. Una discusión a este respecto puede verse también en: Manuel Durán. “Perspectivismo en un capítulo del Quijote". Hispania. 2 (1956): 145-148.

8 Teniendo en cuenta que se trata del análisis de un texto literario, se asume su enfermedad de manera literal como locura, tal y como el texto lo señala. Sin embargo, se recurre a la analogía con el objeto de hacer más explícito el comportamiento del síntoma e hipotetizar su diagnóstico como neurosis de angustia, que de manera general, mejor resume, concentra y explica el concepto de neurosis. Sobre el comportamiento del síntoma, la generación de la histeria y la neurosis, se puede ver Freud, S. El mecanismo psíquico de los fenómenos histéricos. Obras completas. V. 1. Madrid: Biblioteca Nueva, 2003. P.p. 41-50. Igual, téngase en cuenta que la "traición" de Luscinda puede significar para él una nueva pérdida del objeto; es decir, Lucinda, que se había convertido en una metáfora más de su madre perdida, la real causante del deseo (el falo simbólico en el decir de Lacan), se ha perdido de nuevo, y entonces, siguiendo esa huella del deseo sembrada por su madre ausente, fantasea, como en el sueño. En La interpretación de los sueños Freud reelabora esta idea, que viene planteando desde cuando escribió los Tres ensayos para una teoría sexual (Freud, S., 2003; Lacan, J., 1956, p. 33). 
[...] y desde entonces -dice el cabrero-, nunca más le vimos, hasta que de allí a algunos días salió al camino a uno de nuestros pastores, y sin decidle nada se allegó a él, y le dio muchas puñadas y coses, y luego se fue a la borrica del hato, y le quitó cuanto pan y queso en ella traía, y con extraña ligereza, hecho esto, se volvió a entrar en la sierra (Óp. Cit., p. 159).

Sin embargo, agobiado por los padecimientos de su dolor, intenta explorar su interior para zafarse de su manía con las personas que, como "chivos expiatorios", encuentra en su camino. Un interior fluyente de insultos intransferibles a un(os) supuesto(s) fementido(s), don Fernando(s), a quien(s) le(s) dice: «aquí, aquí me pagarás la sinrazón que me hiciste: éstas manos te sacarán el corazón, donde albergan y tienen manida todas las maldades juntas, y principalmente, la fraude y el engaño» (Óp. Cit., p. 159). Aquel engaño amoroso estimula la producción de odio que él parece entrever en el corazón de los otros, pues como comenta Ricoeur: «nada se parece más al secreto de uno que el secreto del otro» (Óp. Cit., p. 212) (el subrayado es mío).

Sin lograr en estas salidas fallidas la libre y sana satisfacción de sus deseos (al no poder vengar su ofensa, o por una errónea verbalización de sus dolencias), se retira e interna en la oscuridad de la montaña manteniendo un ciclo de apariciones, golpizas y nuevas desapariciones. Como el síntoma, la satisfacción de Cardenio en estas falsas salidas se realiza en la decepción y el displacer. Se diría entonces, recurriendo a la misma analogía, que la tranquilidad habitual de Sierra Morena ha cambiado por las dificultades que presenta un intruso en el procesamiento de sus dolencias para su posterior adaptación al sistema.

Los cabreros y demás personas con quienes Cardenio se encuentra, son para él hombres como don Fernando, y por lo tanto se transforman para el enfermo en la imagen de su enemigo: un hombre ausente pero fantaseado ${ }^{9}$ a través de estos perso-

9 Freud establece las diferencias entre el fantasma y la fantasía. En sus apreciaciones sobre la dinámica de la transferencia, Freud dice que: «El neurótico no puede amar ni dirigir su libido hacia los objetos del mundo exterior, ya que la libido está volcada hacia objetos de najes que frustran el cobro de su venganza. Ellos, como don Fernando, simulan para él ser ladrones del amor de Lucinda, y por lo tanto, obstaculizan la satisfacción de sus deseos. ¿Cuáles deseos? Muy posiblemente los que ligan su fantaseo a un virtual acontecer sexual entre Luscinda y don Fernando con circunstancias vividas o imaginadas por él desde su temprana niñez. El relato informa que, desde su infancia, la ha soñado como su esposa, y que cuando le señala a Luscinda a don Fernando a la luz de una vela, a éste le despierta un gran apetito sexual. Un hecho que Cardenio percibe pero que no descifra en su estado consciente; sin embargo, posteriormente instiga por manifestarse causándole dolor. Mientras que en don Fernando florece la llama de la sexualidad, en Cardenio progresa el amor. «El amor, -diría Octavio Paz en La llama doble (1993) - es la metáfora final de la sexualidad» (Óp. Cit., p. 106). La sexualidad reprimida de Cardenio conlleva a la expresión de un amor deslucido, demarcando el camino de las manifestaciones neuróticas. La correlación de fuerzas en uno y otro personaje podrían ser útiles a la hora de caracterizar su locura.

La sintomatología de un hombre que lleva seis meses escondido en la selva experimentando repetidos, esporádicos e inexplicables episodios de violencia sin muestras de mejoría, indica, como bien se observa, que se trata de unos síntomas bajo los cuales subyace la presencia de un problema básico por descubrir (Óp. Cit., p. 158). La aspereza en el hablar de Cardenio, acompañada de inesperados ataques físicos hacia los otros, demuestra fallas en la liberación de sus deseos libidinales reprimidos en su hablar por el mal manejo de la transferencia. La expresión de sus cíclicos síntomas neuróticos

la fantasía». Freud parte de una frustración de la satisfacción. En términos lacanianos se puede decir: «no hay proporción sexual, el goce está malogrado y el neurótico suple ese vacío con la fantasía" (Ons, S., 2009). Anterior a éstas observaciones, Freud precisa en Estudios sobre la histeria que: "Con frecuencia, la causa de los fenómenos patológicos, más o menos graves que el paciente presenta, está en los sucesos de la infancian, que son despertados luego con el acaecimiento del accidente. Freud, S., 2003, p.p. 41-2) ¿Cuáles fenómenos? Es lo que habría que dilucidar teniendo en cuenta la información existente sobre niñez del enfermo, que para el caso que nos ocupa es escasa. 
lo mantiene al margen del devenir social, viviendo como «un bruto animal» (Óp. Cit., p. 161).

\section{Don Quijote, sexualidad y transferencia ${ }^{10}$}

Freud, que leía a Cervantes, no solamente acertó en detectar el valor de la transferencia en el proceso de la cura psicoanalítica, sino en destacar la importancia del papel de la sexualidad en la etiología de la histeria. Freud, en el largo desarrollo de sus Estudios sobre la histeria, descubrió que en el amor del paciente hacia la persona del médico infería la transmisión de un síntoma con un sentido u orientación desconocido. Más allá de lo que Breuer vio hacia 1880 con el uso del método catártico y sus posteriores planteamientos sobre la histeria, Freud se dio cuenta de que el verdadero destinatario de dicho amor no era el analista, sino la necesidad de expresar otra $\operatorname{cosa}^{11}$ (Laplanche, p. 428). Esa otra cosa a que Freud hace referencia, está inscrita en el deseo inexplorado de Cardenio, ansioso de expresar un no se sabe qué en sus encuentros fallidos con el otro.

El encuentro de Cardenio con cada uno de los personajes que halla en su camino deja una experiencia acumulada para seguir buscando la forma en que esa otra cosa pueda y deba ser expresada

10 Freud se pregunta, al analizar las causas del fracaso del tratamiento psicoanalítico de Ida Bauer (caso Dora): «¿Qué son las transferencias? Reediciones o productos facsímiles de los impulsos y fantasías que han de ser despertados y hechos conscientes durante el desarrollo del análisis y que entrañan como singularidad característica de su especie la sustitución de una persona anterior por la persona del médico. 0 para decirlo de otro modo: toda una serie de sucesos psíquicos anteriores cobran de nuevo vida, pero ya no como pasado, sino como relación actual con la persona del médico. Algunas de estas transferencias se distinguen tan solo de su modelo en la sustitución de la persona. Son, pues, insistiendo en nuestra comparación anterior, simples reproducciones o reediciones invariadas. Otras muestran un mayor artificio; han experimentado una modificación de su contenido, una sublimación, según nuestro término técnico, y pueden incluso hacerse conscientes apoyándose en alguna singularidad real, hábilmente aprovechada, de la persona o de las circunstancias del médico. Estas transferencias serán ya reediciones corregidas y no meras reproducciones" (Freud, S., 2003, p. 998).

11 En "Comunicación preliminar" de Estudios sobre la histeria de Freud y Breuer (1893), se precisa que el trauma se sexualiza y el síntoma, como recuerdo fallido del trauma, testimonia la dificultad de olvidar lo traumático. En consecuencia, la constante aparición de esa otra cosa es una indicación de la relación entre el hecho traumático y la sexualidad infantil del paciente, que será necesario develar en la terapia (Freud, S., 2003, p.p. 41-50). (transferida) de forma correcta para la clínica. Esta es quizás la forma de ilustrar el progreso de la técnica psicoanalítica representada en esta mini historia. Tal vez por eso, Cervantes introduce en escena al cura y al barbero, dos personajes clínicamente diferentes a los anteriores, con quienes el enfermo logra al final de un ininterrumpido y largo hablar, el restablecimiento de su armonía mental. Dos personajes que surgen luego de las pistas dispersas en el texto, que ligan la sexualidad del paciente con esa otra cosa que el Caballero del Bosque no logra transferir, ni el de La Triste Figura interpretar.

Cervantes aprovecha su ingenioso juego de perspectivismo narrativo para indicar en el texto el papel de la sexualidad en sus relaciones con la locura. Por ello, pospone el desarrollo de los hechos de Cardenio al capítulo XXVII, e inserta en los capítulos XXV y XXVI «las cosas extrañas que en Sierra Morena le sucedieron al valiente caballero de la Mancha» (Óp. Cit., p. 166). La extrañeza de los hechos está relacionada con la escritura de una carta de amor a Dulcinea del Toboso por un Don Quijote «en carnes y pañales... descubriendo cosas que por no verlas otra vez», dice Sancho, prefiere dar la vuelta e irse (Óp. Cit., p. 176).

Como un "perverso polimorfo"12, impudoroso de su desnudez, propio de un niño en su fase preedípica, Don Quijote refiere en aquella espontánea expresión de su sexualidad las causas de su locura. La voz narrativa dice que «volvió Sancho la rienda a Rocinante, y se dio por contento y satisfecho de que podía jurar que su amo quedaba loco». Don Quijote, "como un niño juguetón, en "carnes y pañales" ", sugiere al lector una interpretación más aguda de las relaciones entre sexualidad, amor,

12 Precisa Freud sobre la «Disposición perversa polimórfica que, es muy interesante comprobar que bajo la influencia de la seducción puede el niño hacerse polimórficamente perverso; es decir, ser inducido a toda clase de extralimitaciones sexuales. [...] La adquisición de las perversiones y su práctica encuentran, por tanto, en él muy pequeñas resistencias, porque los diques anímicos contra las extralimitaciones sexuales, o sea el pudor, la repugnancia y la moral, no está aún constituidos en esta época de la vida infantil o su desarrollo es muy pequeño" (Freud, S.,, 2003, p. 1205). 
represión y "locura"13. El descubrimiento del inconsciente, corazón del psicoanálisis, comienza entonces a develar su forma.

No es por pura coincidencia que el más reconocido de los locos sobre la faz de la tierra, gracias a este extraordinario ejercicio de ficción literaria, sin ropas y sin máscaras sociales, envíe con su gran amigo una carta a su ideado amor, haciéndole saber además que, a pesar de su edad, su sabiduría y sus andanzas, en las cabriolas de su desnudez se deberán encontrar las respuestas al permanente interrogante de su "locura", que se plantea en la totalidad de la obra.

En Cardenio, los hechos descritos tienden lazos referenciales para explicar su "locura", pues elementos no decodificados de su sexualidad se expresan en aquel también frustrado amor por Luscinda, motivo de su hablar, y por lo tanto, causante en principio de su enfermedad. De nuevo la analogía: si Dulcinea del Toboso es la promotora de la "locura" de Don Quijote, Lucinda lo es para Cardenio, y por supuesto, bajo la plataforma circulante de la libido, sexualidad o deseo, fantaseando en su ser inconsciente.

Dos siglos después de publicada la obra de Cervantes, el fundador del psicoanálisis sienta en la sexualidad la bases de su teoría, y para explicarla, propone los conceptos de pulsión, libido y transferencia. La sexualidad sugerida en el texto literario necesita ser deconstruida para auscultar sus formas de funcionamiento y expresividad. Sobre la libido -la energía pulsional en su expresión sexual-, en su

13 Carroll B. Johnson hace un exhaustivo análisis sobre la sexualidad en el Quijote, y precisa, entre otros aspectos, que: «la identidad de Don Quijote, es el resultado de haber huido de sus propios deseos eróticos inaceptables". En su libro Madness and lust: a psychoanalitical approach to don Quixote, el autor desarrolla esta idea planteando que Don Quijote escapa de la casa en la que vive con dos mujeres hogareñas (su sobrina, de 22 años, y un ama de casa, de 40), y como consecuencia sobrevienen una serie de fantasías eróticas en sus años 50 que le hacen la vida intolerable (Johnson, C. B., 1983. Cap. 1-2). Véase también el ensayo La sexualidad en el Quijote. Edad de Oro, IX (1990). 125-136. Centro virtual Cervantes. Literatura. En Línea: Diciembre 10 de 2010: http://cvc.cervantes.es/ literatura/quijote_antologia/johnson.htm\#np6

Guillermo Sánchez Medina sostiene que «En Don Quijote, el personaje que representa la fantasía en contraposición con la realidad, también se puede vislumbrar no ya el odio puro llevado a la violencia sádica o masoquista, sino el resentimiento del hombre con la mujer. Don Quijote nunca hace el amor; [... ] y su amor por la aventura es un amor desviado» (Sánchez Medina, G., 1969, p.p. 104-5). necesidad de manifestarse, estimula la psiquis a crear representaciones simbólicas que, a veces, como en el caso de Cardenio, afectado por un trauma, tropiezan con personajes o elementos que disponen en el sujeto un refuerzo de la represión y la consecuente frustración de la manifestación de lo real ${ }^{14}$. Es decir, ocurren por la fuerte presencia del "yo", manifestaciones de displacer afectivo re-conducido y ramificado hacia otras vertientes de salida con expresiones de rabia o violencia en el enfermo. En tal caso, se está hablando de satisfacciones sustitutivas de la pulsión sexual, también llamadas en psicoanálisis síntomas, como los de Cardenio, de quien el cabrero dice:

Y estando en lo mejor de su plática, paró y enmudeciese, clavó los ojos en el suelo por un buen espacio, en el cual todos estuvimos quedos y suspensos, esperando en qué había de parar aquel embelecimiento, con no poca lástima de verlo; porque por lo que hacía de abrir los ojos, estar fijo mirando al suelo sin mover una pestaña gran rato, y otras veces cerrarlos apretando los labios y encarnando las cejas, fácilmente conocimos que algún accidente de locura le abría sobrevenido (Óp. Cit., p. 159).

Desde la clínica psicoanalítica ${ }^{15}$, tanto la neurosis de Cardenio como la psicosis ${ }^{16}$ de Don Quijote, tie-

14 Sobre lo real, Estanislao Zuleta -parafraseando a Lacan- precisa que: «Es aquel residuo que se resiste a su domesticación por lo simbólico, a su reducción; es como el grano de arena en el corazón de la perla, es ineliminable aunque se quisiera. Es aquel punto de referencia seguro e inamovible a cuyo alrededor la estructura subjetiva se organiza. El síntoma, en cierto modo, es una formación simbólica que engloba algo de lo real insoportable. Lo real se construye por una organización de lo simbólico con lo imaginario, y si no se logra esa organización, se tiene un delirio (Zuleta, E., 1986, p. 46).

15 Diríamos con Lacan, desde "la clínica estructural", que aborda las enfermedades mentales partiendo de la noción de estructura y no desde la visión engañosa de los fenómenos, como lo practica la nosología psiquiátrica que redefine periódicamente la clasificación de las enfermedades mentales por la dificultad de establecer fronteras. Tanto la neurosis de Cardenio como la psicosis de Don Quijote compartirían la misma estructura, excepto por la función del nombre del padre, que tanto en la psicosis como en la neurosis marcan diferencias expresadas en su sintomatología. Algunas investigaciones fundadas en el psicoanálisis, como la de Carlos Feal, acentúan la locura de Cardenio como psicosis argumentando que no se trata de una simple represión, sino del fenómeno de la forclusión del nombre del padre. Véase: Feal, Carlos. Against the law. Mad lovers in don Quixote". Quixotic desire: psychoanalytic perspectives on Cervantes. Ed. El Saffar, Ruth Anthony y De Armas W., Diana. Ithaca: Cornell University Press, 1993, p.p. 179-199.

16 Considerando el enfoque de la nosología psiquiátrica actual, Don 
nen como causa común un desarrollo problemático de su temprana sexualidad. En Cardenio, enfermo de neurosis, la ambivalencia de la libido para ser exteriorizada por la fuerte presencia de un "yo" prevenido en exceso a la satisfacción del deseo, empeora su estado de salud mental. Se carece, en la primera parte del relato, de un analista idóneo para ayudar a conducir y transferir la libido sin traumatismos hacia un nuevo destino. Desafortunadamente, de esta metodología no saben ni ganaderos ni cabreros, tampoco Sancho ni Don Quijote. En consecuencia, la locura de Cardenio, como la de Don Quijote, se hacen inmanejables casi hasta el final de los relatos, respectivamente.

La libido -precisa Freud- es motor de la cura, pero también puede llegar a ser un obstáculo si el enfermo neurótico no detecta el deseo del analista, esto es, la búsqueda, persecución o pillaje de la libido retrotraída (introversión es la palabra usada en la traducción de Luis López Ballesteros), fantaseando en el mundo inconsciente que el analista persigue tras el hablar pausado del paciente ${ }^{17}$ (Freud, 2006, p. 1649). Ello explica la ambivalencia re-creativa en ${ }^{18}$ Cardenio, en sus cíclicos encuentros con unos y con otros hasta antes de hallarse con el cura y el barbero: en un comienzo, muestra disposición para hablar, pero después de varios minutos de fallida escucha se transforma en una persona agreste y violenta. La

Quijote cumpliría criterios para un Trastorno Delirante y esto se argumenta con base en la génesis del delirio, la sintomatología y sus rasgos formales. Asimismo, se propone el diagnóstico de Trastorno Psicótico Compartido para la pareja protagonista (Don Quijote y Sancho). Véase: Rosana, Corral Márquez y Tabares, Rafael: Aproximación psicopatológica a El Quijote. Revista de la Asociación Española de Neuropsiquiatría. 85 (2003) Madrid: AEN, 2003. En línea: abril 01 de 2010: http://scielo.isciii.es/scielo.php?pid=S0211$57352003000100003 \&$ script=sci_arttext\&tlng=es

17 Véase el texto: Sobre la dinámica de la transferencia, en donde se define la transferencia como un motor y un obstáculo de la cura. Igualmente, el concepto "introversión de la libido" tomado por Freud de Jung.

18 Escribo "en" y no "de" porque Cardenio es un personaje recreado por Cervantes, lo que explica no solamente la ambigüedad del personaje, sino de la novela misma como género literario que permite, como diría Octavio Paz, urevivir un instante o serie de instantes». Estos "poderes rítmicos del lenguaje" con personajes ambivalentes como Cardenio también se observan en Aura (1962) de Carlos Fuentes, tema sobre el cual la crítica literaria ha escrito en extenso (Paz, 0., 2003, p. 225). soledad y el autoanálisis ${ }^{19}$, que tal vez busca realizar en la oscuridad de Sierra Morena, son tan ineficaces como el hablar con quien no sabe escuchar ni manejar la aparición de la transferencia. Por la gravedad del accidente causante de su neurosis tampoco está en condiciones de sublimar su libido en actividades creativas, y explota de forma violenta o se interna en la oscuridad de la montaña.

La aparición de una transferencia negativa ${ }^{20}$ en sus diferentes encuentros, mal recibida y mal manejada por sus interlocutores, produce en él no sólo reacciones de desagrado, sino de enfado y violencia. Tanto el cabrero, como Don Quijote y Sancho, dejan fluir también sus sentimientos contra-transferenciales sobre la figura de Cardenio, quien ve a sus escuchas como a sus personajes enemigos. ¿Cuáles enemigos? Inicialmente al "fementido don Fernando", usurpador del amor de Luscinda, la última repetición de su amor maternal nuevamente perdido, ahora bajo el engaño y la traición. Igualmente don Fernando, quien debido a sus hechos y muy a pesar de su linaje, es asimilado por Cardenio más con los obreros y trabajadores del campo, que con gente de su misma clase social.

Respecto a la niñez de Cardenio, el Caballero del Bosque o el Roto²1, en el decir de Don Quijote,

19 Sostiene Silvia Onis que «la transferencia es un concepto fundamental para el psicoanálisis: resorte de la cura, principio de su poder y condición de su eficacia. No hay análisis sin transferencia, razón por la cual el autoanálisis es imposible» (Onis, S., 2009).

20 La transferencia negativa consiste básicamente en hostilidad y desconfianza hacia el analista, $y$, en principio, parece imposibilitar el trabajo de la cura. Regularmente, un sentimiento negativo es expresado hacia el analista como reflejo de algo similar sentido por el paciente respecto de su padre o madre (Freud, S., 2003, p. 1651).

21 Estos dobles paródicos de insistente aparición en Don Quijote, dan cuenta, entre otras cosas, de la posición artística de Cervantes, como precursor de la novela moderna. Se trata, como lo propone Bajtin en su estudio contextual de Rebeláis, de un género dialógico, polifónico, carnavalesco, ambiguo, donde aparecen los dobles y las máscaras como expresión de la ambivalencia bajo la cual subyacen muchos de esos posibles motivos psicológicos que animan el descubrimiento de la obra. El mismo Bajtin precisa la forma como a través de la individualidad de cada personaje, el autor le va dando un sentido de totalidad a la producción artística (Bajtin, M. M., [1982] 2005, p. 265). 
es muy poca la información que el texto suministra para hacer inferencias respecto a los sentimientos infantiles transferenciales propios de la cura psicoanalítica. Sólo se dice que:

Mi nombre es Cardenio, mi patria una ciudad de las mejores desta Andalucía, mi linaje noble, mis padres ricos, mi desventura tanta que la deben de haber llorado mis padres, y sentido mi linaje [...] A ésta Lucinda amé, quise y adoré desde mis tiernos y primeros años, y ella me quiso a mí con aquella sencillez y buen ánimo que su poca edad permitía. Sabían nuestros padres nuestros intentos (Óp. Cit., p.161-2) (El subrayado es mío).

Aunque la referencia a los padres es mínima, no por ello carece de importancia, pues sirven como indicador de la repetición de eventos de la niñez del personaje que el autor de la obra pone en movimiento como muestra de aquel despliegue de elementos que permiten rastrear las causas de la locura del personaje en estudio.

Respecto de la figura del padre de Cardenio, se puede intuir por los conflictos en el trato con los cabreros, Don Quijote y Sancho, y luego, la buena disposición con el cura y el barbero, que se trata de un hombre honesto, educado y distinguido de aquella Andalucía. Tal ideal de confianza parece realizarse en el rechazo a los primeros y en la aceptación de los segundos en el proceso de la cura. Ello si se tiene en cuenta que, tanto sacerdote como barbero, representan élites sociales de la época y encarnan para Cardenio aquella figura paternal idealizada por él. Respecto a la alusión de su temprano encuentro con Luscinda, su segundo y duradero amor después del desprendimiento de aquel primer amor maternal, se reitera la pérdida del objeto, el dolor ante el hecho y la posterior felicidad por su reencuentro.

\section{El cura y el barbero: un nuevo y acertado ensayo para el manejo de la transferencia}

Mientras este juego de espejos entre sexualidad y locura se produce, Cervantes prepara en los dos capítulos siguientes la llegada del cura y del barbero al encuentro con Cardenio, donde se revelan algunos datos adicionales de la forma de operación de la transferencia. Este hecho marca la diferencia entre las habilidades para manejar el diálogo terapéutico que utilizan los ganaderos, el cabrero, Don Quijote y Sancho, y las del cura y el barbero. Como bien se anota, los primeros salen lesionados sin que Cardenio mejore, mientras que los segundos consiguen su mejoría sin violencia ni dificultades.

Pero, ¿qué es lo que marca la diferencia entre unos y otros para que el fenómeno de la transferencia prospere? Primero, la experiencia de los hechos anteriores la traslada Sancho al cura y al barbero, quienes sorprendidos al escuchar los versos de un "poeta" en la soledad de la montaña, observan que se trata de «un hombre del mismo talle y figura que Sancho Panza les había pintado cuando les contó el cuento de Cardenio» (Óp. Cit., p. 183-4). Esta experiencia es fundamental porque permite, en especial al cura, reconocer los errores cometidos por los otros al encuentro con El Roto y evitar su repetición.

Segundo, la información personal del paciente es fundamental, pues además de los datos suministrados por Sancho sobre Cardenio, el cura y el barbero tienen antes de su real encuentro con él, una impresión adicional cuando le escuchan en la soledad y desde la sombra del bosque, declamar sus versos que «no eran de rústicos ganaderos sino de discretos cortesanos» (Óp. Cit., p. 183). Son versos que metaforizan su dolor, desplazando objetos de sentido como indicadores de las dolencias del alma y profunda expresión del deseo. Los versos dicen:

¿Quién menoscaba mis bienes? Desdenes.

¿Y quién aumenta mis duelos? Los celos.

¿Y quién prueba mi paciencia? Ausencia.

De ese modo en mi dolencia,

Ningún remedio se alcanza,

Pues me mata la esperanza,

Desdenes, celos y ausencia.

¿Quién me causa este dolor? Amor.

¿Y quién mi gloria repugna? Fortuna. 
¿Y quién consciente mi duelo? El cielo.

De ese modo, yo recelo

Morir deste mal extraño,

Pues se aúnan en mi daño

Amor, fortuna y cielo.

¿Quién mejorará mi suerte? La muerte.

Y el bien de amor ¿Quién le alcanza? Mudanza

¿Y sus males quien los cura? Locura.

De ese modo no es cordura

Querer curar la pasión,

Cuando los remedios son

Muerte, mudanza y locura.

(Óp. Cit., p. 183) (Los destacados son míos).

El cura y el barbero saben ahora, a través de este poetizar de Cardenio y de sus acciones violentas en los hechos pasados, acerca de los desplazamientos que, como metáforas o metonimias del lenguaje, en el decir de Lacan, hablan del desplazamiento del deseo en su necesidad de manifestarse. Dice la narración que:

La hora, el tiempo, la soledad, la voz y la destreza del que cantaba, causó admiración y contento en los oyentes, los cuales se estuvieron quedos esperando si alguna otra cosa oían, pero viendo que duraba algún tanto en silencio, determinaron en salir a buscar al músico que con tan buena voz cantaba (Óp. Cit., p. 183).

El barbero, que para la época cumplía las funciones de médico, y el cura, en su posición de salvador de almas en sufrimiento ${ }^{22}$ (o experto en las dolencias

22 Como se anotó antes, Michael Foucault nos recuerda que para la época en la cual se inscribe esta historia, la iglesia católica había adoptado una actitud compasiva y caritativa con los "enfermos de locura". Quizás por ello la idea de Cervantes de incluir la figura del cura en este relato. Pero más que eso, es a mi entender, un progreso en el entendimiento de la locura como enfermedad(es) con fronteras poco claras. de psique), se hacen a una mejor impresión de Cardenio. Saben de su pasado, de su posición social, del funcionamiento de su intelecto, de la educación que lo distingue, de sus dolencias del alma (psique) que ocasionan su tristeza, y de las dificultades en el proceso de la escucha en sus encuentros anteriores con el otro. Esta información clínica de su ahora paciente prepara el escenario propicio para el desarrollo de la terapia y el trabajo de la cura.

A lo anterior, y como tercer punto, se le suma la figura del cura, de quien se dice, «era un hombre bien hablado (como el que ya tenía noticia de su desgracia, pues por las señas le había conocido)», infiriéndose de esta afirmación la admiración y la diferencia con los ganaderos, el cabrero, Don Quijote y el mismo Sancho, y como tal, el respeto del enfermo hacia quien escucha y la deferencia de éstos hacia el enfermo, como premisa para significar la distancia necesaria entre paciente y analista (Óp. Cit., p. 184).

Cuarto, de nuevo el compromiso bilateral de respeto, bajo el cual el hablante y los escuchas inscriben el diálogo. El enfermo y el "médico" han establecido un pacto de trabajo que persigue un fin específico: la recuperación total de Cardenio en un ambiente "clínico" previamente planeado para ello, quedando claro que no se trata de un hecho accidental, como las experiencias anteriores, o de una conversación entre amigos similar a una relación dual, sino de un acto en el cual, y como bien lo enseña el mismo texto en un diciente juego de palabras, el enfermo de locura transfiere sus dolencias al cura (al especialista) hasta alcanzar su cura (Óp. Cit., p. 183). Cardenio, además de expresar su complacencia por las personas que ahora "el cielo" ha puesto en su camino, y de expresar disculpas, pena y vergüenza por lo que los otros piensen de su locura, «comenzó su lastimera historia casi por las mismas palabras y pasos que le había contado a Don Quijote y al Cabrero pocos días atrás». Por su parte, dice el narrador, el cura y el barbero deseaban de Cardenio «saber de su mesma boca la causa de su daño», y «le rogaron se lo contase, ofreciéndole de no hacer otra cosa de la que él quisiere en su remedio o consuelo» (Óp. Cit., p. 184). 
Pero más sugestivo aún, y como quinto punto, la actitud de sumo interés mostrada por el cura hacia el hablante, también detectada por éste. Un proceso interrelacional entre dos posiciones de trabajo diferentes, permite el establecimiento de una confianza recíproca como estímulo a la espontaneidad y a la libre asociación de ideas. De parte del cura se dice que, además del ruego y la persuasión para que dejara «aquella vida tan miserable», a Cardenio le gustó cuando "oyó que le habían hablado en su negocio como es cosa sabida (porque las razones que el cura le dio así lo dieron a entender)» (Óp. Cit., p. 184). Razones que bien se diferencian de los consejos y de la presencia de los otros. La presencia de un analista idóneo, en este caso el cura, facilita el vencimiento de algunas de las resistencias, permitiendo el surgir de una transferencia positiva ${ }^{23}$ hacia la persona del cura, quien personifica, quizás, a aquella figura paterna referenciada por Cardenio en su presentación inicial.

Finalmente, la forma magistral como el cura interpela y demanda de Cardenio la continuidad del relato sin que se produzcan alteraciones que impidan alcanzar exitosamente al recuerdo. El cura, oficiando de "psicoanalista”, interviene dos veces la larga exposición de Cardenio. En la primera ocasión, Cardenio parece exhausto en su hablar, y temeroso del posible acabose de sus metáforas y de sus significantes, se increpa asimismo por la carencia de significados ante el amor y la vida. Advertido del advenimiento de "la cosa" por ese vacío de significantes, reclama la presencia del otro. Entonces comenta: «No os canséis, señores, de oír estas digresiones que hago,

23 Freud define la transferencia positiva como "los sentimientos amistosos y afectuosos hacia el médico. La transferencia positiva se descompone luego, a su vez, en la de aquellos sentimientos amistosos o tiernos que son capaces de conciencia y en la de sus prolongaciones en lo inconsciente. Con respecto a éstas últimas, demuestra el análisis que proceden de fuentes eróticas, y así hemos de concluir que todos los sentimientos de simpatía, amistad, confianza, etc., que entrañamos en la vida, se hallan genéticamente enlazados con la sexualidad, y por muy puros y asexuados que nos los representemos en nuestra auto percepción consciente, proceden de deseos puramente sexuales, habiendo surgido de ellos por debilitación del fin sexual. Primitivamente no conocimos más que objetos sexuales, y el psicoanálisis nos muestra que las personas meramente estimadas o respetadas de nuestra realidad pueden continuar siendo, para nuestro psiquismo inconsciente, objetos sexuales» (Freud, S., 2003, p. 1651). que no es mi pena de aquellas que puedan y deban contarse sucintamente y de paso, pues cada circunstancia suya me parece a mí que es digna de un largo discurso» (Óp. Cit., p. 189).

Se observan, de un lado, las múltiples razones que encuentra en Luscinda para referenciar su deseo, $y$, del otro lado, la búsqueda del analista como puente que llene el vacío de significantes ante la presencia de "la cosa". El cura, percibiendo la inminente aparición del deseo, le hace saber al enfermo que «no sólo no se cansaba en oírle, sino que les daba mucho gusto las menudencias que contaba, por ser tales que merecían no pasarse en silencio, y la misma atención que lo principal del cuento» (Óp. Cit., p. 189).

Con esa intervención, sencilla pero prudente, interpreta el sentir del paciente y lo motiva a continuar con su hablar haciéndole saber que todo lo que diga es importante, pues asociando una idea con la otra, bien se puede llegar a "lo principal del cuento". Empíricamente, el cura sabe de la importancia de este momento y de la necesidad de darle continuidad al diálogo. Más tarde, Freud dirá que «esta lucha entre el médico y el paciente, entre el intelecto y el instinto, entre el conocimiento y la acción, se desarrolla casi por entero en el terreno de los fenómenos de transferencia», como el que surge en Cardenio en esta etapa del relato (Freud, 2006, p. 1653).

No está de más agregar la prudencia del barbero frente al hablar de Cardenio. Ni una sola intervención sobre los hechos registra el texto, excepto su acompañamiento al cura en forma silenciosa, pero enalteciendo el momento de la cita con su presencia y sabiduría. Si él, quien para la época oficiaba como médico o como dentista y ostentaba ese reconocimiento social igualmente percibido por Cardenio, no interpela al cura, entonces asiente con su silencio el conocimiento y buen desempeño del trabajo que éste realiza. Contribuye de esta manera a crear un ambiente de tranquilidad y respeto para realzar este cuadro que traerá la salud mental y física de Cardenio. Desde el punto de vista ético, esta es la gran enseñanza proyectada en el texto: la recuperación de una vida para la vida a través de una novedosa técnica empíricamente desarrollada por unos personajes que se erigen desde entonces como modelos. 


\section{El deseo del analista, la cadena asociativa y el lugar de la falta}

En este momento de la narración es ejemplarizante el postulado lacaniano del "deseo del analista" (Freud, S., s.f., p. 256) por la forma como el cura estimula la continuación del relato para "reconducir la demanda de la pulsión" (Onis, 2009). Cardenio, encantado con la sensación de protección suministrada por sus escuchas, es decir, sintiendo los efectos de un presunto amor paternal, insinúa que las digresiones que siguen sobre Luscinda no son importantes, «que no es mi pena de aquellas que puedan y deban contarse sucintamente y de paso, pues cada circunstancia suya me parece a mí que es digna de un largo discurso» (Cervantes, Óp. Cit., p. 189). Lo que sigue en el relato es el momento más doloroso de su sentir, pues significa la bendición matrimonial, que es la entrega sexual de Luscinda a don Fernando por mandato de la Iglesia y su consecuente pérdida definitiva. Hay un final a sus posibilidades de goce fantaseadas en su hablar que el cura hábilmente reconduce. Un enamoramiento con un destino perdido ha surgido en la terapia, pero es bien correspondido por la calidez y la distancia con la cual el cura lo estimula a seguir hablando.

Desde el punto de vista técnico, este ejercicio de la libre asociación de ideas, evidente en la historia, hace manifiesto el desempeño de la resistencia como obstáculo al fluir de la transferencia (Freud, S., 1912 (2006), p. 1650) requerida por el diálogo. En el hablar de Cardenio, se presenta un primer momento en el cual se detienen las asociaciones y se interrumpe la palabra. La resistencia (temor, pena a seguir contando) como un límite a ese saber del hablante, exige en un segundo momento la intervención del analista para destrabar la interrupción de la "cadena asociativa" y jalonar la continuidad del diálogo (Freud, 2006, p. 1650). Este procedimiento lo realiza el cura de manera exitosa en aquella primera intervención hablada, pues está además presente con su presencia, dedicándole a Cardenio la atención necesitada.

Si «cada circunstancia suya me parece a mí que es digna de una largo discurso», como reza el texto, se asume de Cardenio la continuidad de un hablar ahora vacío de significantes (Cervantes, Óp. Cit., p. 189). Es el momento en el cual el analista entra a ocupar el lugar de la falta, estableciendo un puente en el relato (Freud, 1915, p. 1695). La respuesta del cura ilustra de manera ejemplar el hecho, pues expresa gusto en oírle y considera que tales menudencias son tan importantes como "lo principal del cuento" (Cervantes, Óp. Cit., p. 189). A diferencia de la interrupción agreste de Don Quijote a Cardenio en la primera parte de la mini historia, en este fluir de Cardenio frente al cura y el barbero, la libre asociación de ideas facilita el vencimiento de las resistencia para el hallazgo de "la cosa" en la búsqueda de la cura.

A lo anterior se le suma la actitud de imparcialidad del cura sobre el hablar de Cardenio. Tal actitud configura los principios técnicos de Abstinencia y de Neutralidad ${ }^{24}$, a tener muy en cuenta durante la

24 "La cura psicoanalítica ha de desarrollarse, dentro de lo posible, en la abstinencia [...] Recordaréis que lo que hizo enfermar al sujeto fue una privación, y que sus síntomas constituyen para él una satisfacción sustitutiva". Más adelante hace precisiones sobre el Principio de Neutralidad: «Por nuestra parte, rehusamos decididamente adueñarnos del paciente que se pone en nuestras manos y estructurar su destino, nuestros ideales y formarle, con orgullo creador, su destino, a nuestra imagen y semejanza [...] no se debe educar al enfermo para que se asemeje a nosotros, sino para que se libere y consume su propio ser». En alusión a J. Putnam, argumenta que: «tampoco aceptar su demanda de colocar al psicoanálisis al servicio de una determinada concepción filosófica del universo e imponer ésta a los pacientes para su mayor ennoblecimiento espiritual». También esto constituiría un acto de violencia, aunque encubierta por la más noble intención. En Psicoanálisis y teoría de la libido, sostiene: «El analista respeta la peculiaridad del paciente, no procura modificarla conforme a sus propios ideales, y le es muy grato ahorrarse consejos y despertar, en cambio, la iniciativa del analizado" (Freud, S., 2003, p.p. 2459, 60, 61, 2672).

En Consejos al médico en el tratamiento psicoanalítico también precisa: «El médico debe permanecer impenetrable para el enfermo y no mostrar, como un espejo, más que aquello que le es mostrado [...] No podemos entonces extrañar que se deje llevar por una comprensible ambición y se esfuerce en hacer algo excelente de aquella persona a la que tanto trabajo le ha costado libertar de su neurosis, marcando a sus deseos los más altos fines. Como médicos debemos ser tolerantes con las flaquezas del enfermo y satisfacernos con haber devuelto a un individuo, aunque no se trate de una personalidad sobresaliente, una parte de su capacidad funcional y de su goce [...] La ambición pedagógica es tan inadecuada como la terapéutica" En otro de sus apartes, hablando sobre "La transferencia", comenta que: "Puedo, además asegurarles que estáis en un error si creéis que aconsejar y guiar al sujeto en las circunstancias de su vida forma parte de la influencia psicoanalítica. Por el contrario, rechazamos siempre que nos sea posible ese papel de mentores, y nuestro solo deseo es el de ver al enfermo adoptar por sí mismo sus decisiones» (Freud, S., 2003, p.p. 1659, 2392). 
terapia, pues se busca evitar no solo la satisfacción del deseo del enfermo en la persona del analista, sino la intervención del analista asumiendo compromisos con el paciente y/o prestándose para dar consejos. El médico no es ni deberá actuar como un amo buscando autosatisfacerse en la terapia que conduce. Si de lo que se trata es de ayudar al enfermo a que se haga consciente de una parte de su saber no sabido causante de su enfermedad, la intervención indebida del analista con los supuestos antes mencionados obstaculiza la libre asociación de ideas, con la introversión del "ello" y posteriores reacciones inesperadas.

En este caso, la narración se ciñe a estos principios. El cura a su encuentro con Cardenio sólo lo invita a que le cuente qué le pasa debido a que vive aislado en esa montaña y luce muy mal. Con ello consigue sentarlo a hablar; luego, en su segunda intervención, interpreta ligeramente el sentir de Cardenio para pedirle que siga hablando, $y$, finalmente, cuando termina con su

larga plática tan desdichada como amorosa; -dice la voz narrativa- y al tiempo que el cura se prevenía para decirle algunas razones de consuelo le sorprendió una voz que llegó a sus oídos que decía lo que se dirá en la cuarta parte de esta narración (Cervantes, Óp. Cit., p. 191).

Lo que sigue en las próximas páginas es el desarrollo de una terapia un poco similar para Luscinda. El cura no dice más porque Cardenio, con su buen hablar, ha dicho lo suficiente. Él es ahora consciente de su verdad. Ha logrado sublimar su pulsión procesando adecuadamente su angustia, y entonces se dispone a reconstruir la amistad y demás trabajo creativo alrededor de los otros.

Se puede decir entonces que el hilo de la comunicación llegó hasta su otro extremo y una nueva conexión con la realidad les espera. Tal hilo es el mismo que el autor pone en boca de Sancho cuando, al principio de la mini historia, encuentran en la maleta de Cardenio, abandonada junto a su mula muerta, un librillo con un soneto escrito en borrador. En éste, el autor relata sus pesares amorosos. En la lectura del soneto por parte de Don Quijote, San- cho confunde Fili con hilo, y aprovecha la cacofonía para direccionar la comunicación en la búsqueda "de la cosa"25: «Por esa trova-dijo Sancho-no se puede saber nada, si ya no es por ese hilo que está ahí se saque el ovillo de todo». Líneas más abajo le dice Don Quijote a Sancho que él no dijo hilo sino Fili, que «sin duda es el nombre de esa dama de quien se queja el autor deste soneto; y a fe que debe ser razonable poeta o yo sé poco de arte» (Cervantes, Óp. Cit., p. 156). El ovillo mencionado por Sancho habrá que buscarlo entonces siguiendo el hilo del deseo metaforizada en el relato. Cardenio, gracias a un excelente trabajo de escucha, a un buen manejo de la transferencia y a un buen ejercicio de interpretación, ha logrado hacer consciente lo inconsciente, y como ha dicho Freud al final del Caso Dora, «ha sido ganado(a) de nuevo para la vida» (Freud, S., 2006, p. 878). El reencuentro con Luscinda, como hecho accidental más no prioritario en su proceso de recuperación mental, está a la vuelta de un par de capítulos.

\section{La creencia en el analista}

La creencia en el analista es otro de los elementos adyacentes a la terapia psicoanalítica con buenos resultados en el caso de Cardenio. Una creencia supeditada al símbolo de sabiduría que encarna el analista. Dice Jacques-Alain Miller que «en la terapia psicoanalítica, el psicoanalista hace de supuesto sujeto del saber [...] Es un lugar muy peligroso porque puede llevar al psicoanalista a identificarse al buen Dios» (Miller, J-A., 2006, p. 56). Identificado con esa figura paternal, el enfermo ve en éste a su liberador, a aquel que todo lo sabe y está en condiciones de desatar las amarras de su incomprensión. Los psicoanalistas en la historia de esta disciplina, prosigue Miller,

se identificaron gustosamente con la divinidad, tienen incluso una infatuación muy especial, puesto que como por función se supone que saben, no se sienten obligados a saber nada; quiere decir que

25 Sobre la actitud relativista en el uso del lenguaje por parte de Cervantes, véase el texto de Leo Spitzer, Perspectivismo lingüístico en El Quijote. Lingüística e historia literaria, Madrid: Gredos, 1955 (1948), p.p. 135-187. 
pueden muy bien nadar en la ignorancia y eso no impide que siendo su posición la del otro en la experiencia, ellos se consideran perfectos (Miller, J-A., 2006, p. 56).

La presencia del cura y del barbero en el relato incorporan todas estas características en una sociedad todavía ignorante en la identificación de la "locura" y sus formas de tratamiento. El uno simboliza al curador de almas (la psique) y el otro, experto en los problemas del cuerpo, como si el texto cervantino adujera de antemano que los problemas del alma repercuten en el dolor del cuerpo ${ }^{26}$. Para Cardenio, este cuadro diferencial del cura y el barbero respecto a sus primeros interlocutores, aumenta su confianza y posibilidades de éxito en sus deseos de lograr una salida a sus dolencias del alma. El cura y el barbero son, en parte, portadores de una idea salvadora de sustento religioso. La creencia en el analista del texto en estudio está entonces acompañada en un creer en un otro que se supone que sabe, ya por sus conocimientos académicos o por su "cercanía" con la divinidad como reflejo de una idea aristotélica de perfección. Creencia sobre la cual se afirma Cardenio en la configuración de la confianza que supone el reencuentro con el padre, perdido y añorado. Como se recuerda, da gracias al cielo «por socorrer a los buenos, y aun a los malos», y al comienzo de su presentación recuerda a su patria, su linaje y la riqueza de sus padres, una añoranza que se intensifica en la soledad de la montaña (Cervantes, Óp. Cit., p.p. 184, 161).

En definitiva, el cura reproduce ese hallazgo, ese reencuentro con aquel que lo sabe todo, (aunque no lo sepa) que está en condiciones de salvarlo por su situación de papá, de clérigo y de profesional en el conocimiento de los problemas del alma. Es con él, y no con Don Quijote, con quien Cardenio finalmente alcanza la cura. Es el cura quien finalmente demuestra "saber más" que los demás sobre el funcionamiento de este mecanismo psicoterapéutico observable en este caso de ficción literaria. Es a él a

26 Freud y Breur demostrarían, en los estudios sobre la histeria, los vínculos entre los síntomas histéricos y sus relaciones con la psiquis (Freud, S. y Breuer, 1893 (2003), p.p. 41-50). quien finalmente Cardenio le cree. Cree que el cura le va ayudar porque es cura y debe "saberlo", y porque tiene, como otro ser humano, la obligación moral de hacerlo. Pero además, porque públicamente la prédica deontológica implícita de su profesión se lo exige. En él, Cardenio descarga su confianza. Posee el cura, entonces, esos valores agregados del personaje distinguido de la narración. Aunque fabricado con ese fin, estereotipa el surgir de una figura médica asimilable en muchos aspectos a la del psicoanalista de hoy.

\section{La contra-transferencia}

Freud daba a conocer en 1910 los nuevos avances del psicoanálisis en el tratamiento de la neurosis. Sostiene el texto que: se nos ha hecho visible la "transferencia recíproca"
que surge en el médico bajo el influjo del enfer-
mo sobre su sentir inconsciente, y nos vemos
muy inclinados a exigir, como norma general, el
reconocimiento de esta "transferencia recíproca"
por el mismo médico y a su vencimiento (Freud,
S., 2006).

Sugiere que «todo principiante inicie su actividad con un autoanálisis» (Freud, S., 2006, p. 1566).

¿Por qué Don Quijote, quien tiene por ley «desfacer entuertos, prodigar el bien y evitar el mal», fracasa en su deseo de ayudar a Cardenio a recobrar la cordura? Por lo mismo que indica Freud: porque su sentir inconsciente manifiesta la aparición del fenómeno de la transferencia recíproca debido a que está "loco", y como tal, hubiese necesitado mucho antes del encuentro con Cardenio hacer consciente su saber inconsciente para sanarse y estar quizás en disposición de desempeñar a futuro el papel de buen escucha. Desde el comienzo del diálogo con el enfermo, irrumpe en él el fenómeno de la transferencia recíproca, no obstante las observaciones de Cardenio: «con ninguna pregunta ni otra cosa no interrumpiréis el hilo de mi triste historia, porque el punto que lo hagáis en ese quedará lo que fuere contado». A lo cual, dice la voz narrativa: «Estas razones del Roto trajeron a la memoria a Don Quijote el cuento que le había contado su escudero, cuando no acertó el número de las cabras que habían pa- 
sado el río, y se quedó la historia pendiente. Pero volviendo al Roto, prosiguió diciendo» (Cervantes, Óp. Cit., p. 161).

A pesar de su intención de ser prudente y respetuoso en la escucha, y de la advertencia del cabrero de la fácil reacción violenta de Cardenio, su ánimo delirante de "guardar el decoro de la caballería" perturba la posibilidad del desarrollo del diálogo tanto al principio como en el intermedio, cuando de nuevo el enfermo comenta el pedido de Luscinda del libro de Caballerías Amadis de Gaula (Cervantes, Óp. Cit., p.p. 184, 164). La revelación de sentimientos de amor y de odio inunda el sentir de Don Quijote generando el resurgimiento del fenómeno de la contra-transferencia para desatar de nuevo su delirio. Con un largo sermón, Don Quijote replica a Cardenio, pero éste, a su vez, contra-replica a Don Quijote. Para ambos, envueltos en la discusión, sobreviene un accidente de locura, con reacciones violentas de parte y parte que terminan con la plática $\mathrm{y}$ con aquel noble deseo de cura.

Freud, consciente de los peligros del surgimiento de la "transferencia recíproca", aconseja la idoneidad profesional del terapista acompañada de un buen ejercicio de análisis previo para evitar traumatismos como el que se comenta. No basta con las buenas intenciones y el altruismo que motiva una práctica de ayuda, debido a que una intervención errónea o inesperada por parte del médico puede fácilmente terminar con el procedimiento, con el deseo de reanudarlo después, o hasta con la vida de una persona. La historia dice que el enfermo se internó otra vez en la montaña, y por las experiencias anteriores, podría suponerse que sería hallado de nuevo, como de hecho ocurrió. Sin embargo, la posibilidad de encontrarlo con vida era tan solo eso, una posibilidad, y la de retomar la terapia, otra posibilidad todavía más lejana.

Respecto al manejo de la "transferencia recíproca" por parte del cura, se anotó antes que el conocimiento previo del caso, con todos los elementos de observación y preparación adicionales, fueron de utilidad. A pesar de la posición social del cura, del supuesto conocimiento de la "verdad" social y moral por su condición de religioso, ninguna reprimenda, ni consejos, ni deseos de re-educar a Cardenio afloran durante la plática. No obstante su posición como hombre que vive y siente, que tiene experiencias de vida, y que como ser humano puede entender el saber del otro, la prudencia, neutralidad y gran capacidad de interpretación al momento de hablar, demostraron, empíricamente, ser en este cuadro de ficción las mejores herramientas para hacer exitosa la transferencia, la contra transferencia y lograr la cura.

\section{Conclusiones}

Con base en este relato, Las desdichas de Cardenio en el ingenioso hidalgo Don Quijote de la Mancha, se ha realizado un ejercicio de "análisis aplicado" para observar el funcionamiento del fenómeno de la transferencia y demás mecanismos asociados, que en últimas, permiten también saber de la "locura" de Cardenio, réplica artística de Don Quijote. En los diferentes encuentros de $\mathrm{El}$ Roto con los personajes del relato, se van mostrando los errores y aciertos que permiten el perfeccionamiento de la técnica. Un desarrollo empírico de un proceso de cura mental que, visto a la luz del pensamiento psicoanalítico desarrollado desde Freud, resulta ser de gran ilustración.

El valor del lenguaje como primer recurso transmisor de la realidad del inconsciente es de vital importancia en la transferencia psicoanalítica, debido a que engancha el sentir de aquel saber no sabido que se intenta descubrir durante la terapia. Dentro de la talk terapy-como también se le denomina- el saber escuchar es requisito fundamental para que el buen y saludable hablar prospere, pues quien interrumpe invade el mundo que el enfermo busca esclarecer, provocando reacciones y resistencias expresadas con ira, ausentismo, desdén o violencia. Reacciones regularmente enlazadas a principios de autoridad afincadas en la vida inconsciente del enfermo ansioso por descubrir en el encuentro con el otro las razones de su "locura".

Como en la Gradiva de Jensen (1903), Freud supo observar en la realidad del poeta réplicas, que de manera fantástica podrían confirmar muchos de sus hallazgos. Sin embargo, y muy a pesar de 
la aparente fidelidad de todas estas descripciones artísticas sobre el funcionamiento de la mente humana y de su reconocida afición por el arte, supo reconocer no sólo la diferencia entre un estudio psicoanalítico y un desarrollo literario, sino también que el poeta expresa grandes saberes que resultan ser de utilidad en la consolidación de postulados teóricos, como el que se extrae del calambur que se forma entre cura, el cura y locura de los versos citados por Cardenio. La agudeza y seriedad requerida por la observación clínica en sus primeros años como médico neurólogo, son muy comparables a su interés por el saber literario, y como en el descubrimiento del complejo de Edipo, su trabajo a priori con sus pacientes lo observó después graficado en la literatura de creación de origen griego y egipcio. $\mathrm{El}$ arte, delata entonces aquellos objetos de sentido sobre realidades humanas perceptibles por el lectorespectador. Se infiere la competencia del arte para escribir desde siempre sobre lo que no está escrito. Vasos comunicantes entre el saber de la clínica y el saber de la antropología, la sociología, la cultura y la literatura, permiten entender la metapsicología que define al psicoanálisis.

No hay duda que dichos saberes fueron también observados por Freud en El Quijote de Cervantes, primera novela moderna cargada de un saber indiscutible hasta el punto de hacer reír. Y es que la risa, la carcajada, la alegría, la gracia, la pantomima, la parodia, el disfraz, el desenmascaramiento, las expresiones de ingenuidad, el chiste, como parte de aquellos elementos propios del ambiente carnavalesco característicos de la novela moderna y de suma evidencia en El Quijote, permiten la transgresión de las normas para el redescubrimiento de ese saber inconsciente, propio del infante reprimido por la ley, para convertirlo en sujeto social. La "locura" $27 \mathrm{de}$ Don Quijote, y en consecuencia la de sus personajes, auspicia la caída de las máscaras sociales presentes en el mundo de la obra, facilitando el enriquecimiento humano hecho posible y visible en la fiesta y el carnaval. Cardenio, el cura, Sancho, el barbero, el cabrero, don Fernando y Luscinda, y todos los lectores que viven con Don Quijote su "locura", reconocen las miles de facetas que le dan forma a la humanidad. El renacimiento trajo consigo este despertar artístico con tremendas explosiones de sabiduría humana que expertos como Bajtin y Julia Kristeva han sabido analizar respecto de las obras de arte. El fenómeno de la trasferencia, uno de los cuatro conceptos fundamentales del psicoanálisis, es vivencial en todos. En el largo hablar de Cardenio y en las piruetas de Don Quijote se sintetiza esta realidad. Freud, agudo observador de los fenómenos culturales y lector de las novelas cervantinas, no dudó en teorizar en el El chiste y sus relación con el inconsciente (1905) parte de ese rico saber carnavalesco expresado en estas obras.

Alrededor del manejo del fenómeno de la transferencia, entendida de la manera más sencilla en el natural y espontáneo encuentro entre dos personas, como el ¡deje hablar!, o, mejor dicho, japrenda a escuchar!, se ha podido reconocer gran parte de esa riqueza humana contenida en El Quijote.

27 Recuerda Estanislao Zuleta que «En El Quijote la relación entre la locura y la cordura se vuelve un verdadero tejido. Los más cuerdos resultan muchas veces, al lado de Don Quijote, verdaderos delirantes" (Zuleta, E., 2001, p. 23). 


\section{Bibliografía}

Bajtin, M. (1974). La cultura popular en la Edad Media y el Renacimiento. El contexto de François Rabelais. Barcelona: Barral.

(2005). Estética de la creación verbal. México, D.F.: Siglo XXI Editores.

Cervantes, M. (1997). Novelas ejemplares: la ilustre fregona. El casamiento engañoso. Coloquio de los perros. Madrid: Castalia.

El Saffar, R. (1986). Crítica literaria de Madness and lust: a psychoanalitical Approach to Don Quixote. Comparative Literature, 38, p.p. 73-83.

Fabian, J. (2002). Time and the other. How anthropology makes its object. New York: Columbia University Press.

Feal, C. (1993). Against the law. Mad lovers in Don Quixote. En R. El Saffar y D. de Armas (Eds.), Quixotic desire: psychoanalytic perspectives on Cervantes (p.p. 179-199). Ithaca: Cornell University Press.

Freud, S. (2006). Estudios sobre la histeria. Obras completas, V. 1. Madrid: Biblioteca nueva.

(2006). La interpretación de los sueños. Obras completas, V.1. Madrid: Biblioteca Nueva.

(2006). Análisis fragmentario de una histeria (caso Dora). Obras completas, V. 1. Madrid: Biblioteca Nueva.

(2006). El chiste y su relación con el inconsciente. Obras completas, V. 1. Madrid: Biblioteca Nueva.

(2006). El delirio de los sueños en la Gradiva de W. Jensen. Obras completas, V. 2. Madrid: Biblioteca Nueva.

(2006). El poeta y los sueños diurnos. Obras completas, V. 2. Madrid: Biblioteca Nueva.

(2006). El porvenir de la terapia psicoanalítica. Obras completas, V. 2. Madrid: Biblioteca Nueva.

(2006). La dinámica de la transferencia. Obras completas, V. 2. Madrid: Biblioteca Nueva.

(2006). Recuerdo, repetición y reelaboración. Obras completas, V. 2. Madrid: Biblioteca Nueva.

(2006). Puntualizaciones sobre el amor de transferencia. Obras completas, V. 2. Madrid: Biblioteca Nueva.

Foucault, M. (2006). History of Madness. J. Murphy y J. Khalfa (Trad.). Londres: Routledge.
Grinberg, L. y Rodríguez, F. (1993). Cervantes as cultural ancestor of Freud. En R. El Saffar y D. de Armas (Eds.), Quixotic desire: psychoanalytic perspectives on Cervantes (p.p. 23-33). Ithaca: Cornell University Press.

Johnson, C. (1990). La sexualidad en el Quijote. En Edad de Oro, IX, p.p. 125-136.

(1983). Madness and lust: a psychoanalytical approach to Don Quixote. Berkeley: University of California Press.

Lacan, J. (1988). El seminario sobre La carta robada; Del sujeto por fin cuestionado; Función y campo de la palabra y del lenguaje en psicoanálisis. Escritos. Buenos Aires: Editorial Siglo XXI. (14 edición).

(1991). Los escritos técnicos de Freud, Libro I; El yo en la teoría de Freud y en la técnica psicoanalítica, Libro II; Las psicosis, Libro III; Las formaciones del inconsciente, Libro V; Los cuatro conceptos fundamentales del psicoanálisis, Libro XI; El reverso del psicoanálisis, Libro XVII; Aún, Libro XX. El Seminario. Buenos Aires: Editorial Paidós.

(1973). Los cuatro conceptos fundamentales del psicoanálisis. J. Miller (Ed.). Buenos Aires: Paidos.

Laplanche, J. y Pontalis, J. (2007). Diccionario de psicoanálisis. Buenos Aires: Paidós (9a. ed.).

Miller, J. (1984). Quehacer del psicoanalista. Recorrido de Lacan. Buenos Aires: Manantial.

Moreno, B. (2009). Perspectivas de la investigación psicoanalítica en Colombia. Medellín: Universidad de Antioquia.

Ons, S. (2009). Lecturas freudianas: La transferencia 1. Barcelona: IAEU.

Parkin-Gounelas, R. (2001). Literature and Psychoanalysis. New York: St. Martin's Press.

Paz, O. (2003). La ambigüedad de la novela. El arco y la lira. México D.F.: Fondo de Cultura Económica.

(1993). La llama doble. Amor y erotismo. Barcelona: Seix Barral.

Riley, E. (1994). "Cipión" writes to "Berganza" in the Freudian Academia Española. Cervantes: Bulletin of the Cervantes Society of America, V. 14, 3-18. Documento recuperado de http://www.h-net.org/ cervantes/ csa/artics94/riley.htm, Julio 01 de 2010.

Ricoeur, P. (1974). Psicoanálisis y cultura. En U. Eco, L. Goldmann y R. Bastide (Comps.), Sociología contra psicoanálisis. Bruselas: Ediciones Martínez Roca. 
Sánchez, G. (1969). Amor, odio y perversión. Bogotá: Tercer mundo.

Spitzer, L. (1948). Perspectivismo lingüístico en el Quijote. Lingüística e historia literaria (p.p. 135- 187). Madrid: Gredos.
Zuleta, E. (1985). El pensamiento psicoanalítico. Bogotá: Hombre Nuevo Editores.

(2001). El Quijote: un nuevo sentido a la aventura. Bogotá: Hombre Nuevo Editores. 